\title{
So long sulphur
}

\author{
Why Nature Chemistry spells sulfur with an ' $f$ '.
}

Many decisions must be made when setting up a new scientific journal. These range from perhaps the more fundamental considerations, such as what subjects will be covered and what article types will be featured, to practical issues of spelling and style. Leading up to the launch of Nature Chemistry, a number of these choices had to be made, and the one that raised more than a few eyebrows at the time - and still continues to provoke debate even now - was the decision to spell element number 16 with an 'f' instead of 'ph'.

Why the consternation? Well, a quick geography lesson may help to explain. Although Nature and the Nature Research Journals have editors dotted around the globe in various offices, each title can claim a particular city as its home base. For example, Nature Nanotechnology and Nature Physics call London home, whereas Nature Biotechnology and Nature Chemical Biology are based on the other side of the Atlantic Ocean in New York and Boston, respectively. It should come as no surprise, therefore, that the UK-based journals use Oxford English spelling and those in the US have adopted American English.

Nature Chemical Biology may say that an author's favorite color is gray, but Nature Physics would say that an author's favourite colour is grey. In a similar vein, the UK journals - including Nature itself — spell sulphur with 'ph' and the US titles spell sulfur with an 'f'. So, with Nature Chemistry based in London, why do we not follow suit and use the 'ph' variant? The answer boils down to the fact that it's not simply a case of Oxford English versus American English when it comes to naming chemical elements.

It is the International Union of Pure and Applied Chemistry (IUPAC) who deal with questions of nomenclature and naming when it comes to chemical elements and compounds. And so when IUPAC decided that element 16 should be spelled as 'sulfur' — either in 1971 (ref. 1) or 1990 (ref. 2) depending on the source - there should be no argument about whether there should be a 'ph' in there or not. It is not a question of American or Oxford English spelling, it is a given name - and 'correcting' such a name to a different spelling is wholly inappropriate. What would Fred Flintstone say if we insisted on spelling his name Phred Phlintstone! Just to hammer the point home, IUPAC only accepts alternative spellings for two elements, and neither of them is sulfur: 'aluminum' and 'cesium' are fair game, although Nature Chemistry uses aluminium and caesium.

For those who defend the 'ph' version of sulfur, there is little in the way of support in etymological arguments. In general, the use of 'ph' as an 'f' sound occurs in words that are derived from Greek - the 'ph' replaces the Greek letter 'phi' $(\phi)$. A good example of this substitution can be found if we move just to the left in the periodic table and consider element 15, phosphorus, which means 'lightcarrier' in the original Greek. Element 15 also has its spelling woes - an additional 'o' often creeps in to make it 'phosphorous'.
A fascinating and detailed account ${ }^{3}$ of the history of the name of element 16 can be found elsewhere, but the bottom line is that sulfur is not a Greek loan word and so there is no 'phi' that needs to be replaced with 'ph. The Greeks called element 16 'theion', which is similar to the prefix 'thio' that we commonly encounter when describing sulfur-containing compounds today.

The word 'sulfur' can be traced to Latin, where the oldest form seems to be sulpur, which, over time, became sulphur and then finally sulfur - the first example of the latter spelling is thought to date back the third century. Only in English did the 'ph' remain for the ' $\mathrm{f}$ ' sound - in other European languages the ' $\mathrm{f}$ ' won through: azufre (Spanish), schwefel (German), soufre (French), zolfo (Italian). Interestingly, why the change from 'sulphur' to 'sulfur' occurred in the United States during the early part of the twentieth century remains something of a mystery, as other 'ph' words have persevered in American English.

Language is our servant, not our master and it evolves to meet our needs. And in the case of sulfur, there seems to be no good reason to continue using the 'ph' form other than perhaps a mistaken sense of spelling jingoism.

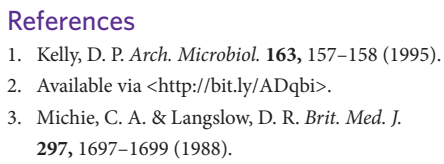

\section{Hello 112}

\section{Another 'superheavy' element is officially welcomed to the table.}

Sigurd Hofmann and his team at the GSI Centre for Heavy Ion Research in Darmstadt, Germany, made ${ }^{1}$ the first atom of element 112 way back in 1996, but it has only recently been officially recognized ${ }^{2}$ as a new element, even though its chemistry has already been explored ${ }^{3}$. Based on further work by the GSI team and independent confirmation of their findings by researchers at RIKEN in Japan, the criteria set by IUPAC for the discovery of new chemical elements have now been fulfilled.
Currently, element 112 goes by a couple of different names. One is 'eka-mercury', which follows the style of provisional names that Mendeleev gave to predicted elements yet to be discovered. 'Eka' is derived from the Sanskrit word for 'one', and eka-mercury is the element one place below mercury in the periodic table. 'Ununbium' is the rather unromantic and systematic place-holder name given to element 112 by IUPAC.

Now that Hofmann and his team have officially been credited with the discovery of element 112, however, they get to choose what it will be called - subject to IUPAC approval. The team has been responsible for naming elements 107-111; three of them after people and two after places. Now the speculation begins on what 112 will be named after.

\footnotetext{
References

1. Hofmann, S. et al. Z. Phys. A 354, 229-230 (1996).

2. Barber, R. C. et al. Pure Appl. Chem. doi:10.1351/ PAC-REP-08-03-05 (2009)

3. Eichler, R. et al. Nature $447,72-75$ (2007)
} 